\title{
Review
}

\section{Particular HLA-DQ molecules play a dominant role in determining susceptibility or resistance to Type 1 (insulin-dependent) diabetes mellitus}

\author{
E. Thorsby and K. S. Rønningen \\ Institute of Transplantation Immunology, The National Hospital, Oslo, Norway
}

\begin{abstract}
Summary. Genes in the HLA complex are by far the most important in determining genetic predisposition or resistance to Type 1 (insulin-dependent) diabetes mellitus. In this review evidence is presented that the HLA genes mainly involved are those encoding some particular HLA-DQ molecules. Both among Black, Caucasian and Japanese subjects particular cis or trans encoded DQ molecules are significantly associated with susceptibility, while others are associated with resistance. A varying degree of susceptibility or resistance seems to be conferred by these DQ molecules, where those determining resistance are dominant over those determining susceptibility. The degree of genetic predisposition to develop Type 1 diabetes carried by an individual would therefore be the result of his or her particular combination of DQ molecules. A primary association to particular DQ molecules explains previously found associations to other HLA complex genes by linkage disequilibrium. Some mechanisms by
\end{abstract}

which particular DQ molecules may determine susceptibility or resistance are also discussed. Potential islet beta-cell reactive $\mathrm{CD} 4+\mathrm{T}$-cells may escape negative selection (deletion) in the thymus, but normally become anergized or remain ignorant extra-thymically. However, under particular circumstances they may be triggered. The DQ molecules associated with Type 1 diabetes susceptibility may preferentially bind and present triggering and/or beta-cell derived peptides to such $\mathrm{T}$ cells, causing beta-cell destruction. The finding that particular DQ molecules determine susceptibility may lead to new methods of preventing development of Type 1 diabetes in susceptible individuals.

Key words: Type 1 (insulin-dependent) diabetes mellitus, genetic susceptibility or resistance, HLA-DQ molecules, preferential peptide presentation, beta-cell reactive $\mathrm{T}$ cells.
Both genetic and environmental factors are of importance for development of Type 1 (insulin-dependent) diabetes mellitus. This has been demonstrated by a concordance rate of 35-50\% for monozygotic twins [1]. An HLA identical sibling of a Type 1 diabetic patient carries a 15-25\% risk of developing this disease [2]. These figures demonstrate that genes in the HLA complex are by far the most important in determining genetic predisposition. However, the exact genes in the HLA complex which are involved have not yet been determined.

One reason may be the complexity of the HLA associations in Type 1 diabetes. Several different HLA genes have been found to be associated with susceptibility or resistance, and often to variable degrees. Another reason is the strong linkage disequilibrium which exists for genes in the HLA complex; i.e. particular allelic variants are often present together on the same HLA chromosomal complex ( = haplotype). A third reason is that Type 1 diabetes may be a heterogenous disease, where different autoimmune responses may lead to beta-cell destruction.
Recent studies have demonstrated that some HLADQ genes are most strongly associated with Type 1 diabetes susceptibility. This was also corroborated in a recent international study [3]. Here we review evidence that particular HLA-DQ molecules as such play a dominant role in determining susceptibility or resistance. We also discuss possible mechanisms behind the direct involvement of particular DQ molecules.

\section{The HLA complex}

Some of the HLA gene loci known at present are shown in Figure 1, but there are many others such as those presented by Trowsdale and Campbell [4]. The class I and II regions contain genes encoding the HLA cell-membrane molecules. They are composed of an $\alpha$ and a $\beta$ chain heterodimer. The genes encoding the $\alpha$ chain of the classic class I molecules A, B and $\mathrm{C}$ and those encoding both chains of the class II molecules DR, DQ and DP (Fig.2), 


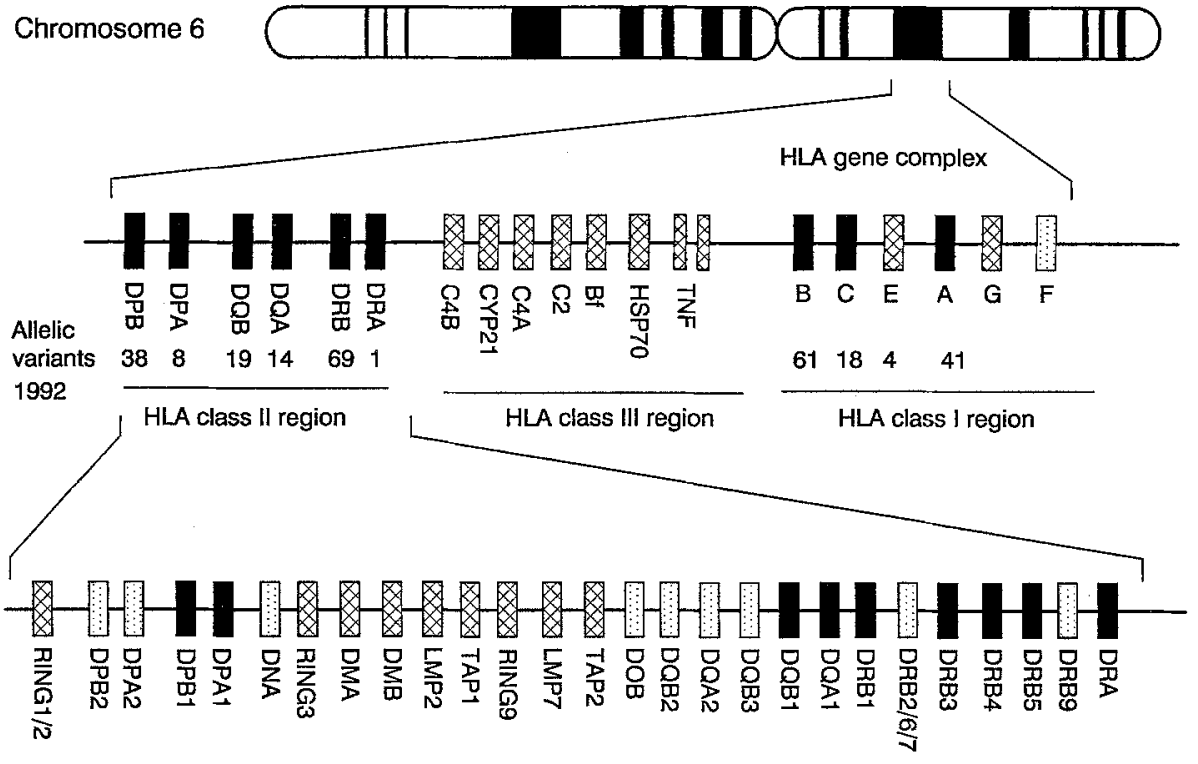

Fig. 1. The HLA gene complex on the short arm of chromosome no. 6 contains many different gene loci. Genes encoding the classic HLA class I and class II cell-membrane molecules $(\mathrm{A}, \mathrm{B}, \mathrm{C}, \mathrm{DR}$, DQ and DP) are marked as filled squares. Genes encoding other molecules are hatched. Genes which are not known to be expressed are marked as open squares with small dots are present in the HLA complex and are very polymorphic (except the DRA gene encoding the DR $\alpha$ chain). The number of allelic variants known is given in Figure 1. They are named by a four digit number, preceded by the name of the locus to which they belong; e.g.DRB1*0101 etc. [5].

The class I and II regions also contain many other genes. In the class II region polymorphic genes involved in processing of protein and transport of peptides from the cytosol to the endoplasmic reticulum i. e. large multifunctional protease (LMP), transporter associated with antigen processing (TAP), as well as others with unknown functions ("really interesting new genes" - RING) are found (Fig. 1). Interspaced between the class I and II regions is the class III region containing genes encoding various complement factors, tumour necrosis factor (TNF) etc. $[4,5]$.

A typical feature of HLA complex genes is linkage disequilibrium. For example, the $A * 0101, B * 0801$, DRB1*0301, DQA $1 * 0501$, and DQB1*0201 genes (encoding the $\mathrm{A} 1, \mathrm{~B} 8, \mathrm{DR} 3$ and $\mathrm{DQ} 2$ molecules, respectively), which all are associated with Type 1 diabetes susceptibility, are very often found together on the same haplotype.

\section{The classic HLA molecules}

The class I molecules A, B and C are present on most cells. In contrast, the class II molecules DR, DQ and DP are mainly present on monocytes, macrophages, dendritic cells and B lymphocytes, but may be induced on many cells by factors such as interferon- $\gamma($ IFN- $\gamma)$. Since both the $\alpha$ and $\beta$ chain genes of DQ and DP molecules are polymorphic, and since class II molecules may be encoded by $\alpha$ and $\beta$ chain genes both in cis position (on the same haplotype) as well as in trans position (on different haplotypes; Fig.2) each individual may potentially express as many as four different variants of DQ or DP molecules or both.
Many HLA molecules have been serologically defined and are named by a number, preceded by the name of the series to which it belongs (A1,B8,DR3,DQ2 etc.). However, genomic typing of the HLA genes is now more and more becoming the method of choice, particularly for typing of the HLA class II variants. Since more HLA genes have been identified than may be serologically defined, and since DQ and DP molecules are encoded by two polymorphic genes, the HLA molecules are more precisely named in accordance with the genes encoding them. For example, the DQA1*0301 and DQB $1 * 0302$ genes encode the DQ molecule $\mathrm{DQ}(\alpha 1 * 0301, \beta 1 * 0302)$, previously called DQ8.

\section{HLA associations in Type 1 diabetes}

Susceptibility to develop Type 1 diabetes was first found associated with the HLA class I molecules B8 and B15, later more strongly with the class II molecules DR3 and DR4 [6], which are in linkage disequilibrium with $B 8$ and $B 15$, respectively. DR3/DR4 heterozygous individuals were found to be at a particularly high risk of developing Type 1 diabetes. Weaker associations were detected to DR1, DR6 and DR8 [7]. In contrast, DR2 and to a lesser extent DR5 were rare among Type 1 diabetic patients; $i$. e. they were associated with resistance [6, 8]. Among Japanese patients, DR4 and DR9 were most prevalent [7].

More recently, Type 1 diabetes susceptibility was found to be even more strongly associated with some DQ genes [9-12]. For example, only individuals carrying the haplotype DR4-DQ8, and not those being DR4-DQ7, were at an increased risk of developing Type 1 diabetes [13]. Thus, the DR4 association was apparently caused by linkage disequilibrium to DQ8. The particularly high risk in DR3-DQ2/DR4-DQ8 heterozygotes might then be explained by an association to a trans-encoded DQ molecule in these individuals [14]. 
The HLA-DQ( $\alpha 1 * 0301, \beta 1 * 0201)$ molecule encoded in cis encoded in trans
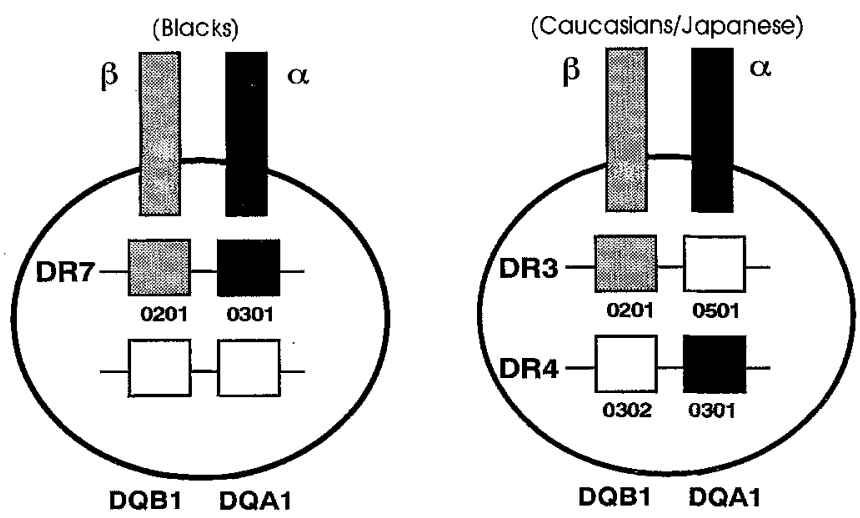

The HLA-DQ( $\alpha 1^{\star} 0301, \beta 11^{*} 0401$ or $\left.\beta 1{ }^{\star} 0402\right)$ molecule encoded in cis

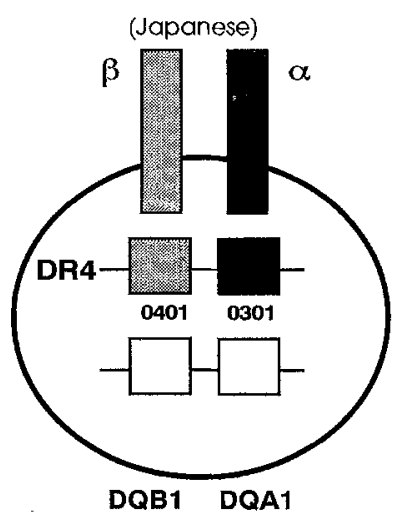
encoded in trans

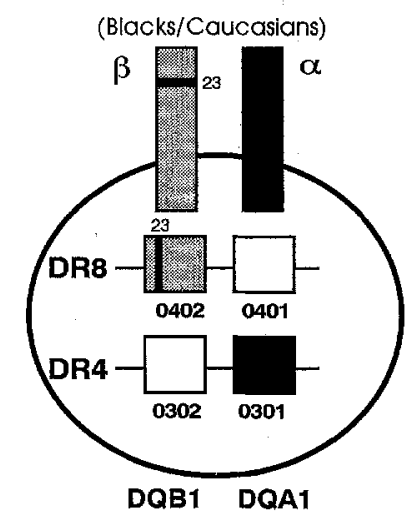

Fig. 2. Top. The DQA1*0301 and DQB1*0201 genes are found on the same haplotype (in cis) among Black Type 1 diabetic patients, while they are most often found on different haplotypes (in trans) among Caucasian and Japanese Type 1 diabetic patients. In both cases the same DQ molecule is encoded and expressed. Bottom. The DQA1*0301 and DQB1*0401 genes are found on the same haplotype (in cis) among Japanese Type 1 diabetic patients, while DQA $1 * 0301$ and DQB $1 * 0402$ are found on different haplotypes (in trans) among Black and Caucasian Type 1 diabetic patients. The DQB1*0401 and 0402 genes only differ at codon 23, thus in both cases a very similar DQ molecule is encoded and expressed

Todd and co-workers [15] suggested that it was the amino acid present at $\mathrm{DQ} \beta$ chain residue 57 which was of importance; DQ molecules having amino acids other than aspartic acid at this residue (non-Asp) were associated with susceptibility, while those having Asp were associated with dominant resistance. However, more recent studies showed the picture to be more complex [16], and Japanese Type 1 diabetes patients mostly have DQ $\beta$ chains of Asp type $[8,17]$.

Khalil et al. [18] proposed that cis or trans encoded DQ molecules consisting of a $\mathrm{DQ} \alpha$ chain having arginine (Arg) at position 52 and a non-Asp $\mathrm{DQ} \beta$ chain were most strongly associated with Type 1 diabetes susceptibility, and that susceptibility correlated quantitatively with the expression of such cis or trans encoded DQ molecules [19]. DQ molecules being DQ $\alpha$ non-Arg and $\mathrm{DQ} \beta$ Asp were supposed to confer protection. However, the relative risk associated with the various Type 1 diabetes susceptibility DQ molecules varied considerably, and Type 1 diabetic patients are found who have protective $\mathrm{DQ} \alpha$ or $\mathrm{DQ} \beta$ chains, or both [20]. This is particularly so among Japanese subjects $[8,17]$.

We suggested recently [21] that Type 1 diabetes susceptibility might be primarily associated with five or six particular cis or trans encoded DQ molecules, which are common for Black and Caucasian subjects, but in part different for Japanese.

Other studies indicated, however, also strong contributions by particular DRB1 genes encoding given variants of DR4 [22], or other genes in the HLA complex [23, 24]. One recent study even indicated association to some TAP gene variants [25]. Thus, it could still not be excluded that the primary association in Type 1 diabetes were to some other or unknown genes in the HLA complex, in strong linkage disequilibrium with given DQ genes, or to particular combinations of genes ("extended haplotypes").

\section{Results of a recent international collaborative study}

As part of the 11th International Histocompatibility Workshop (1991), 981 unrelated Black, Caucasian or Japanese Type 1 diabetic patients were genomically typed for HLA class II alleles, and the results compared with those obtained by typing of 2228 healthy control subjects. The results clearly demonstrated that Type 1 diabetes susceptibility was most strongly associated with particular combinations of DQA1 and DQB1 genes in all three ethnic groups [3]. The combinations demonstrating the strongest and most significant associations are listed in Table 1, together with the corresponding serological DQ and associated DR specificities.

DQA1*0301 together with DQB $1 * 0302$, and DQA1*0501 together with DQB1*0201, in both cases in cis position, were found associated with Type 1 diabetes susceptibility in all three ethnic groups. Among Blacks a significant association was also found to DQA $1 * 0301$ together with DQB1*0201 in cis position (often together with genes encoding DR7), while among Caucasians and Japanese an association with the same two DQ genes in trans position was seen (Fig. 2). The Caucasian genotype most often involved was DR3-DQ2/DR4-DQ8 (Fig.2). However, this genotype also carries another pair of DQ genes in trans position; DQA $1 * 0501$ and DQB $1 * 0302$. Accordingly, a strong association of Type 1 diabetes susceptibility to this trans combination of DQ genes was also seen among Caucasians (Table 1).

In the Japanese Type 1 diabetic patients susceptibility was also associated with DQA1*0301 together with DQB1*0303, and DQA1*0301 together with DQB1*0401, in both cases in cis position. These haplotypes are very rare in Blacks and Caucasians. However, in Blacks and Caucasians, a weaker but significant association was found with the DQA1*0301 and DQB1*0402 genes in trans position. Interestingly, the DQB $1 * 0401$ and DQB $1 * 0402$ genes are very similar, the only known difference being a single nucleotide substitution at codon 23 . Thus, this is another example of a Type 1 diabetes associ- 
Table 1. Some combinations of DQA1 and DQB1 genes associated with Type 1 diabetes susceptibility or resistance in Black, Caucasian and Japanese subjects (modified from [3])

\begin{tabular}{|c|c|c|c|c|}
\hline DQA1,DQB1 & Position $^{a}$ & $\begin{array}{l}\text { Serological } \\
\mathrm{DQ}^{\mathrm{b}}\end{array}$ & $\begin{array}{l}\text { Associated } \\
\mathrm{DR}^{\mathrm{c}}\end{array}$ & $\begin{array}{l}\text { Relative } \\
\text { risk [6] }\end{array}$ \\
\hline \multicolumn{5}{|l|}{ Susceptibility } \\
\hline $\begin{array}{l}0301,0302 \\
0501,0201 \\
0301,0201 \\
0501,0302 \\
0301,0303^{d} \\
0301,0401^{\mathrm{d}} \\
0301,0402\end{array}$ & $\begin{array}{l}c \\
c \\
c / t \\
t \\
c \\
c \\
t\end{array}$ & $\begin{array}{l}\text { DQ8 } \\
\text { DQ2 }\end{array}$ & $\begin{array}{l}\text { DR4 } \\
\text { DR3 }\end{array}$ & $\begin{array}{l}8-12 \\
3-5 \\
5-20 \\
8-35 \\
2 \\
4 \\
5-15\end{array}$ \\
\hline \multicolumn{5}{|l|}{ Resistance } \\
\hline $\begin{array}{l}0102,0602 \\
0103,0603^{e} \\
0103,0601^{d} \\
0501,0301\end{array}$ & $\begin{array}{l}\mathrm{c} \\
\mathrm{c} \\
\mathrm{c} \\
\mathrm{c}\end{array}$ & $\begin{array}{l}\text { DQ6 } \\
\text { DQ6 } \\
\text { DQ6 } \\
\text { DQ7 }\end{array}$ & $\begin{array}{l}\text { DR2,DR11 } \\
\text { DR6 } \\
\text { DR2,DR8 } \\
\text { DR5 }\end{array}$ & $\begin{array}{l}0.2 \\
0.2 \\
0.2 \\
0.2-0.4\end{array}$ \\
\hline
\end{tabular}

${ }^{\mathrm{a}} \mathrm{c}=$ cis or $\mathrm{t}=$ trans position of the DQA1 and DQB1 genes.

${ }^{b}$ Serological DQ specificity encoded by this haplotype.

${ }^{c}$ Associated serological DR specificity most often encoded by this haplotype.

d Only significantly increased or decreased in Japanese subjects. These haplotypes are very rare in Black and Caucasian subjects.

${ }^{\mathrm{e}}$ Only significantly decreased in Black and Caucasian subjects. This haplotype is very rare in Japanese subjects

ation with the same pair of DQ genes, in cis or trans position (Fig. 2) depending on ethnic group [26].

Of the investigated Type 1 diabetic patients, $80-90 \%$ carried one or more of the combinations of DQA1 and DQB1 genes listed in Table 1. Individuals having more than one of these particular combinations of DQ genes were at an increased risk of developing Type 1 diabetes; i.e. some additive effects of these combinations of $D Q$ genes on susceptibility was observed.

Resistance against development of Type 1 diabetes was found associated with several other combinations of DQA1 and DQB1 genes in cis position (Table 1). In all three ethnic groups the strongest resistance was found with $\mathrm{DQA} 1 * 0102$ together with $\mathrm{DQB} 1 * 0602$, or with other DQ genes encoding variants of DQ6. Slightly less resistance was associated with DQA $1 * 0501$ together with DQB1*0301. The DQ-associated resistance was partly, but not completely dominant over the DQ-associated susceptibility. For example, there was a significant reduction in the frequency of the DQA1*0501DQB1*0201/DQA1*0102-DQB1*0602 (DQ2/DQ6) genotype among Caucasian Type 1 diabetic patients compared to healthy control subjects, but some few patients carried such combinations of DQ genes.

\section{Particular DQ molecules as such play a dominant role in determining susceptibility or resistance}

The strongest evidence for this concept is that in all three ethnic groups Type 1 diabetes susceptibility or resistance is significantly associated with particular combinations of DQA1 and DQB1 genes, sometimes in cis position, in other cases either in cis or trans position (Table 1).
Most important is the susceptibility associated with DQA1*0301 and DQB1*0201 in cis or trans position, since the same DQ molecule, e. g. DQ $(\alpha 1 * 0301, \beta 1 * 0201)$, is encoded in either position of the genes [14, 27] (Fig. 2). Equally important is the susceptibility associated with DQA $1 * 0301$ together with DQB1*0401 or 0402 in cis or trans position, since here functionally identical or very similar DQ molecules, e.g. DQ $\left(\alpha 1^{*} 0301, \beta 1 * 0401\right)$ or $\mathrm{DQ}(\alpha 1 * 0301, \beta 1 * 0402)$, are being encoded in either position [28] (Fig.2). In these two cases, therefore, the evidence strongly indicates that the Type 1 diabetes susceptibility is primarily determined by the corresponding cis or trans encoded DQ molecules themselves. A less likely explanation would be a primary association to a combination of two other genes closely linked to these DQA1 and DQB1 genes in cis or trans position, one being centromeric to DQB1, the other telomeric to DQA1 (Fig. 1). Strong association with two genes in cis or trans position also argues against a primary association with given extended HLA haplotypes.

Since in these two cases the corresponding DQ molecules themselves are the best candidates for determining susceptibility, it is likely that the same is true when two DQ genes in cis position are involved.

Is resistance against Type 1 diabetes also determined by particular DQ molecules? Up to now, it has been difficult to ascertain whether resistance is primarily associated with DR2 or DQ6 genes, since the genes involved are often present on the same haplotype. The Workshop studies revealed, however, that the DQA1*0102DQB1*0602 (DQ6) haplotype associated with resistance might carry different DRB1 genes. Among Blacks this haplotype carried DRB1*1503 or DRB1*11 [29], while among Caucasians DRB $1 * 1501$ was carried on this haplotype. Other recent studies have also indicated that resistance is more strongly associated with DQ6 than DR2 [30, 31]. In Japanese, resistance is associated with the DQA1*0103-DQB1*0601 haplotype, which may carry DRB1 genes encoding either DR2 or DR8 (Table 1). Therefore, resistance against Type 1 diabetes also seems to be primarily associated with given DQ molecules, the most important being different variants of very similar DQ6 molecules.

Available evidence thus strongly suggests that some particular DQ molecules determine Type 1 diabetes susceptibility, others determine resistance, while still others are neutral. A varying degree of susceptibility or resistance seems to be conferred by these DQ molecules, whereas DQ molecules which determine resistance are often dominant over those which determine susceptibility. The degree of genetic predisposition for developing Type 1 diabetes carried by an individual would therefore be the result of his or her particular combination of DQ molecules.

This would also explain why the HLA genotype DR3DQ2/DR4-DQ8 is, in particular, strongly associated with Type 1 diabetes susceptibility, since by this DQ genotype (DQA1*0501-DQB1*0201/DQA1*0301-DQB1*0302) four different DQ molecules determining susceptibility are encoded in cis or trans position (Table 1, Fig. 2). Similarly, it is possible to explain why a given DQ molecule in 
some combinations, but not in others may be associated with susceptibility. For example, the Type 1 diabetes susceptibility DQ molecule encoded by DQA1*0301 and DQB1*0201 in trans position in DR3-DQ2/DR4-DQ8 heterozygotes, is not (or to a lesser degree) associated with Type 1 diabetes susceptibility when encoded in trans position in DR3-DQ2/DR4-DQ7 or DR4-DQ8/ DR7-DQ2 heterozygotes. However, in the latter two cases this particular trans encoded DQ molecule is found together with DQ molecules associated with resistance. The Workshop studies revealed that the DQ molecules encoded by DQA $1 * 0301$ and DQB1*0301 (DQ7) or DQA1*0201 and DQB $1 * 0201$ (a variant of DQ2 on the DR7 haplotype) were significantly associated with resistance (data not shown). Another factor may be that DQ genes in the trans posistion do not always lead to expressed DQ molecules, or to DQ molecules expressed to a variable degree. This might depend on the particular combination of $\mathrm{DQ}$ genes in cis and trans position in a given genotype [32]

A primary involvement of the DQ molecules mentioned also explains most previously found DR associations (see above and Table 1). However, this does not exclude that other genes in the HLA complex may contribute. In the 11 th Workshop, no associations were found with any DPA1 or DPB1 alleles. However, a contribution by some DRB1 alleles could not be excluded. By studying Type 1 diabetic patients and HLA-matched control subjects, we were recently unable to confirm the reported association to given TAP gene variants (Rønningen KS, Undlien DE, Ploski R et al., unpublished data).

It should be noted, however, that $10-20 \%$ of the Type 1 diabetic patients studied in the Workshop did not carry any of the combinations of DQA1 and DQB1 genes listed in Table 1. It remains to be established whether other DQ molecules may also confer susceptibility, or whether other genes in the HLA complex may determine susceptibility in these cases. Also, some non-HLA genes are known to play a role [33].

\section{How may HLA-DQ molecules determine Type 1 diabetes susceptibility or resistance?}

Since Type 1 diabetes is probably the end result of a T-cell dependent and probably mainly T-cell mediated autoimmune destruction of islet beta cells [34], HLA cell-membrane molecules have to be involved. HLA class I molecules bind and present peptide fragments of antigen to the T-cell receptors (TCR) of $\mathrm{CD} 8^{+} \mathrm{T}$ cells (mainly cytotoxic), while HLA class II molecules have the same function for $\mathrm{CD}^{*} \mathrm{~T}$ cells (mainly helper $\mathrm{T}$ cells) [35]. The polymorphism of HLA molecules is mainly localized to their peptide-binding clefts [36]. Thus, different variants of HLA molecules differ with respect to the shape etc. of their clefts, which determine which peptides may be bound. Each variant of HLA molecules can only bind one peptide at a time, from a restricted set of peptides [35,37]. Thus, the HLA molecules carried by a given individual will determine the repertoire of antigenic peptides his or her $\mathrm{T}$ cells may be able to recognize.
Since Type 1 diabetes susceptibility seems mainly to be determined by given $\mathrm{DQ}$ molecules, $\mathrm{CD} 4^{+} \mathrm{T}$ cells recognizing given islet beta-cell derived peptides presented by some DQ molecules may be instrumental in the immunopathogenic process, at least initially. How are such self-reactive T cells allowed to develop, and how do they become activated?

During their thymic development $T$ cells are both positively and negatively selected, depending on the TCR they express. T cells with TCR for self-peptide/HLA complexes are first positively selected, then T cells with high affinity TCR for such self-peptide/HLA complexes are negatively selected or deleted. The details of this process are not fully known [38], but the result will be a set of mature $T$ cells mainly able to recognize various peptides derived from foreign proteins in the cleft of self-HLA molecules.

However, negative selection is probably leaky. T cells with TCR for some self-peptides may escape negative selection because the concentration of some self-peptides in the thymus is too low. This may be the case for some potential beta-cell reactive $\mathrm{CD} 4^{+} \mathrm{T}$ cells. Such $\mathrm{T}$ cells may, however, be inactivated (anergized) upon confrontation with islet beta cells, due to the inability of beta cells to provide certain co-stimulatory signals necessary for T-cell activation [39]. Alternatively, the lack of co-stimulatory signals will cause T-cell ignorance; i.e. the $\mathrm{T}$ cells will be neither anergized nor activated [40]. In any case, most escaped potential self-reactive $\mathrm{T}$ cells may not cause autoimmune disease because they are normally not activated.

The situation will be entirely different, however, should some beta-cell derived peptides be presented in sufficient concentration by professional antigen presenting cells (APC) able to deliver the necessary co-stimulatory signals. Animal experiments have shown that $\mathrm{T}$ cells with TCR for virally-derived peptides inserted by transfection in pancreatic beta cells, will normally be ignorant and not cause beta-cell destruction. However, following infection with the corresponding virus, and thus presentation of the virally-derived peptides by professional APC, the $T$ cells may become activated and cause beta-cell destruction [40]. This points to a possible mechanism of Type 1 diabetes (and other autoimmune diseases).

Environmental factors are known to be important for the development of Type 1 diabetes. The nature of such factors is unknown, but certain viruses have been suspected for a long time [41]. Possibly, degradation of some viral proteins may result in peptides showing molecular mimicry to certain beta-cell derived peptides. Following a virus infection, when such viral peptides are presented by professional APC, anergized or ignorant $\mathrm{CD}^{+}{ }^{+} \mathrm{T}$ cells with TCR for the corresponding beta-cell derived peptides may then become activated. Another environmental factor could be cows milk. Children with Type 1 diabetes often have antibodies to a particular peptide derived from bovine serum albumin, antibodies which also react with a pancreatic beta-cell surface protein (p69) that is inducible with IFN- $\gamma$ [42]. If ignorant $T$ cells with TCR for $p 69$ derived peptides exist, they may become activated by confrontation with the bovine serum albumin derived peptide presented by professional APC. Should a viral infection 
later occur in the vicinity of islet beta cells, IFN- $\gamma$ may induce expression of $\mathrm{p} 69$, and thus become a target for T-cell attack.

How and where do the involved DQ molecules exert their effects in these processes? Intra-thymically, the DQ molecules associated with susceptibility may cause positive selection of potentially beta-cell reactive $\mathrm{CD} 4{ }^{+} \mathrm{T}$ cells. In contrast, DQ molecules associated with resistance may cause positive selection of some regulatory or protective $\mathrm{T}$ cells, or deletion of potential beta-cell reactive $\mathrm{T}$ cells (as discussed by Møller et al. [43]).

We consider it more likely that the DQ molecules associated with susceptibility exert their effects extra-thymically. They may preferentially bind and present the peptides involved, both putative triggering peptides and the target beta-cell derived peptides. If DQ molecules are induced by IFN- $\gamma$ and TNF [44] in islet beta cells as a result of infection, the activated $\mathrm{CD} 4^{+} \mathrm{T}$ cells may directly destroy the beta cells. Alternatively, they may recruit CD $8^{+}$ $T$ cells, macrophages or initiate antibody production.

Since Type 1 diabetes is associated with several different DQ molecules, several different beta-cell derived peptides may be involved. Thus, Type 1 diabetes may be a heterogenous disease with respect to the fine specificity of the beta-cell reactive $T$ cells. Alternatively, only one betacell derived peptide is potentially immunopathogenic, which may bind (with different affinity) to all DQ molecules associated with susceptibility. In any case the presence of several different DQ molecules associated with susceptibility may increase the chance of recognition by potential beta-cell reactive $T$ cells. This may explain the additive effects on susceptibility of having more than one of these DQ molecules.

Resistance against Type 1 diabetes by given DQ molecules is more difficult to explain by extra-thymic mechanisms. Nepom [45] has suggested that HLA molecules associated with resistance may tightly bind potential diabetogenic peptides, thus competing with binding of the same peptides to the DQ molecules involved in susceptibility. This mechanism of resistance would, however, require that $T$ cells able to recognize such diabetogenic peptides bound to DQ molecules associated with resistance (e.g. DQ6) should be inhibited or not be allowed to develop.

\section{Conclusion}

The HLA-associated susceptibility or resistance to develop Type 1 diabetes seems mainly to be determined by particular HLA-DQ molecules. A direct contribution by other genes in the HLA complex cannot be excluded, and particular DQ molecules may not determine genetic susceptibility in all cases of Type 1 diabetes. The DQ molecules involved may exert their effects intra-thymically during T-cell development and differentiation, or extrathymically by preferential peptide presentation to potential beta-cell reactive $\mathrm{T}$ cells. The finding that certain $\mathrm{DQ}$ molecules may determine Type 1 diabetes susceptibility may lead to new methods such as the use of blocking pep- tide analogues for preventing the development of Type 1 diabetes in susceptible individuals.

Acknowledgements. We would like to express our gratitude to all those participating in the Type 1 diabetes section of the 11 th International Histocompatibility Workshop [3], and to Drs. L. Sollid, A. Spurkland and F. Vartdal at our Institute for helpful and stimulating discussions.

\section{References}

1. Barnett AH, Eff C, Leslie RDG, Pyke DA (1981) Diabetes in identical twins. Diabetologia 20: 87-93

2. Deschamps I, Lestradet H, Busson M, Hors J (1984) Evaluation of recurrence risk in siblings of diabetic children: importance of age and birth order in relation to HLA genotypes. Diabetes Res 1: $125-135$

3. Rønningen KS, Spurkland A, Tait BD et al. (1993) HLA class II associations in insulin-dependent diabetes mellitus among Blacks, Caucasoids and Japanese. In: HLA 1991. Oxford University Press, Oxford, pp

4. Trowsdale J, Campbell RD (1992) Complexity in the major histocompatibility complex. Eur J Immunogenetics 19: 43-55

5. Bodmer JG, Marsch SGE, Albert ED et al. (1992) Nomenclature for factors of the HLA system, 1991. Tissue Antigens 39: $161-173$

6. Tiwari JL, Terasaki PI (1985) Juvenile diabetes mellitus (insulindependent) In: Tiwari JL, Terasaki PI (eds) HLA and disease associations. Springer Verlag, New York, pp 185-210

7. Awata T, Kuzuya T, Matsuda A et al. (1990) High frequency of aspartic acid at position 57 of HLA-DQ $\beta$-chain in Japanese Type 1 diabetes patients and nondiabetic subjects. Diabetes 39: 266-269

8. Thomson G, Robinson WP, Kuhner MK et al. (1988) Genetic heterogeneity, models of inheritance, and risk estimates for a joint study of Caucasians with insulin-dependent diabetes mellitus. Am J Hum Genet 43: 799-816

9. Owerbach D, Lernmark $\AA$, Platz P et al. (1983) HLA-D region beta-chain DNA endonuclease fragments differ between HLADR identical healthy and insulin-dependent diabetic individuals. Nature 303: 815-817

10. Cohen-Haguenauer O, Robbins E, Busson Met al. (1985) A systematic study of HLA class II- $\beta$ DNA restriction fragments in insulin-dependent diabetes mellitus. Proc Natl Acad Sci USA 82: 3335-3339

11. Festenstein H, Award J, Hitman GA et al. (1986) New HLA DNA polymorphisms associated with autoimmune diseases. Nature 322: 64-67

12. Nepom BS, Palmer J, Kim SJ et al. (1986) Specific genomic markers for the HLA-DQ subregion discriminate between DR4 ${ }^{+}$ insulin-dependent diabetes mellitus and DR4 ${ }^{+}$seropositive juvenile rheumatoid arthritis. J Exp Med 164: 345-350

13. Owerbach D, Gunn S, Gabby KH (1989) Primary association of HLA-DQw8 with Type I diabetes in DR4 patients. Diabetes 38: 942-945

14. Nepom BS, Schwartz D, Palmer JP, Nepom GT (1987) Transcomplementation of HLA genes in Type 1 diabetes. HLA-DQ $\alpha$ and $\beta$-chains produce hybrid molecules in DR3/4 heterozygotes. Diabetes 36: 114-117

15. Todd JA, Bell JI, McDevitt HO (1987) HLA-DQ $\beta$ gene contributes to susceptibility and resistance to insulin-dependent diabetes mellitus. Nature 329: 559-604

16. Rønningen KS, Iwe T, Halstensen TS, Spurkland A, Thorsby E (1989) The amino acid at position 57 of the HLA-DQ $\beta$ chain and susceptibility to develop insulin-dependent diabetes mellitus (type 1 diabetes). Human Immunol 26: 215-225

17. Lundin KEA, Rønningen KS, Aono S et al. (1989) HLA-DQ antigens in Japanese patients with insulin-dependent diabetes 
mellitus. Detection of a DRw8 DQw8 haplotype. Tissue Antigens 34: 233-241.

18. Khalil I, dAuriol L, Gobet M et al. (1990) A combination of HLA-DQ $\beta$ Asp57-negative and HLA-DQ $\alpha$ Arg52 confers susceptibility to insulin-dependent diabetes mellitus. J Clin Invest 85: $1315-1319$

19. Khalil I, Deschamps I, Lepage V, Al-Daccak R, Degos L, Hors J (1992) Dose effect of cis and trans-encoded HLA-DQ $\alpha \beta$ heterodimers in Type 1 diabetes susceptibility. Diabetes 41: 378-384

20. Vicario JL, Martinez-Laso J, Corell A et al. (1992) Comparison between HLA-DRB and DQ DNA sequences and classic serological markers as type 1 (insulin-dependent) diabetes mellitus predictive risk markers in the Spanish population. Diabetologia 35: $475-481$

21. Rønningen KS, Spurkland A, Iwe T, Vartdal F, Thorsby E (1991) Distribution of HLA-DRB1, -DQA1 and -DQB1 alleles and DQA1-DQB1 genotypes among Norwegian patients with insulin-dependent diabetes mellitus. Tissue Antigens 37: 105-111

22. Sheehy MJ, Scharf SJ, Rowe JR et al. (1989) A diabetes-susceptible HLA haplotype is best defined by a combination of HLADR and -DQ alleles. J Clin Invest 83: 830-835

23. Deschamps I, Marcelli-Barge A, Poirier JC et al. (1988) Two distinct HLA-DR3 haplotypes are associated with age related heterogeneity in type 1 (insulin-dependent) diabetes. Diabetologia 31: 896-901

24. Degli-Esposti MA, Abraham LJ, McCann V et al. (1992) Ancestral haplotypes reveal the role of the central $\mathrm{MHC}$ in the immunogenetics of type 1 diabetes. Immunogenetics 36: 345-356

25. Colonna M, Bresnahan M, Bahram S, Strominger JL, Spies T (1992) Allelic variants of the human putative peptide transporter involved in antigen processing. Proc Natl Acad Sci USA 89: 3932-3936

26. Rønningen KS, Gjertsen HA, Iwe T, Spurkland A, Hansen T, Thorsby E (1991) Particular HLA-DQ $\alpha \beta$ heterodimer associated with type 1 diabetes susceptibility in both DR4-DQw4 Japanese and DR4-DQw8/DRw8-DQw4 whites. Diabetes 40: $759-763$

27. Kwok WW, Schwartz D, Nepom B, Thurtle P, Hock R, Nepom GT (1988) HLA-DQ molecules from $\alpha-\beta$ heterodimers of mixed allotype. J Immunol 141: 312-327

28. Gjertsen HA, Lundin KEA, Rønningen KS, Gaudernack G, Thorsby E (1991) A T lymphocyte clone recognizing a DQ $\alpha \beta$ heterodimer encoded in cis by the DR4-DQw4 haplotype and in trans by DR4-DQw8/DR8-DQw4 heterozygous cells. Human Immunol 30: 226-232

29. Garcia-Pacheco JM, Herbut B, Cutbush S et al. (1992) Distribution of HLA-DQA1, -DQB1 and DRB1 alleles in black type 1 diabetes patients and controls from Zimbabwe. Tissue Antigens 40: $145-149$

30. Erlich HA, Griffith RL, Bugawan TL et al. (1991) Implication of specific DQB1 alleles in genetic susceptibility and resistance by identification of type 1 diabetes siblings with novel HLA-DQB1 allele and unusual DR2 and DR1 haplotypes. Diabetes 40: 478481
31. Zeliszewski D, Tiercy J-M, Boitard C et al. (1992) Extensive study of DRB, DQA, and DQB gene polymorphism in 23 DR2positive, insulin-dependent diabetes mellitus patients. Human Immunol 33: 140-147

32. Charron D (1989) Molecular basis of human leukocyte antigen class II disease associations. Adv Immunol 48: 107-159

33. Bain SC, Prins JB, Hearne CM et al. (1992) Insulin gene regionencoded susceptibility to Type 1 diabetes is not restricted to HLA-DR4-positive individuals. Nature Genetics 2: 212-215

34. Cooke A (1990) An overview on possible mechanisms of destruction of the insulin-producing beta cell. Curr Top Microbiol Immunol 164: 125-142

35. Rothbard JB, Gefter ML (1991) Interactions between immunogenic peptides and MHC proteins. Annu Rev Immunol 9: 527565

36. Bjørkman PJ, Saper MA, Samraoui B et al. (1987) Structure of the human class I histocompatibility antigen, HLA-A2. Nature 329:506-518

37. O'Sullivan D, Sidney J, Appella E et al. (1990) Characterization of the specificity of peptide binding to four DR haplotypes. J Immunol 145: 1799-1808

38. Blackman M, Kappler J, Marrack P (1990) The role of the T cell receptor in positive and negative selection of developing $\mathrm{T}$ cells. Science 248: 1335-1341

39. Schwartz RH (1990) A cell culture model for T lymphocyte clonal anergy. Science 248: 1349-1355

40. Zinkernagel RM, Pircher HP, Ohashi P et al. (1991) T and B cell tolerance and responses to viral antigens in transgenic mice: implications for the pathogenesis of autoimmune versus immunopathological disease. Immunol Rev 122: 133-171

41. Bottazzo GF, Bosi E, Bonifacio E, Mirakian R, Todd I, PujolBorrell R (1989) Pathogenesis of type 1 (insulin-dependent) diabetes: possible mechanisms of autoimmune damage. Brit Med Bull 45: 37-57

42. Karjalainen J, Julio MD, Martin MD et al. (1992) A bovine albumin peptide as a possible trigger of insulin-dependent diabetes mellitus. N Engl J Med 327: 302-307

43. Möller E, Böhme J, Valugerdi MA, Ridderstad A, Olerup O (1990) Speculation on mechanisms of HLA associations with autoimmune diseases and the specificity of autoreactive T lymphocytes. Immunol Rev 118: 5-19

44. Pujol-Borrell R, Todd I, Doshi M et al. (1987) HLA class II induction in human islet cells by interferon- $\gamma$ plus tumour necrosis factor or lymphotoxin. Nature 326: 304-306

45. Nepom GT (1990) An unified hypothesis for the complex genetics of HLA associations with Type 1 diabetes. Diabetes 39: $1153-1157$

Dr. E. Thorsby

Institute of Transplantation Immunology

The National Hospital

N-0027 Oslo

Norway 